\title{
Clinical Rhabdomyolysis With Acute Kidney Injury Secondary to High-Intensity Rosuvastatin Use: A Case Report
}

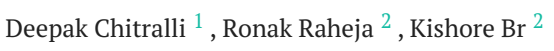 \\ 1. Nephrology, Columbia Asia Referral Hospitals Yeshwanthpur, Bengaluru, IND 2. Internal Medicine, Columbia Asia \\ Referral Hospital Yeshwanthpur, Bengaluru, IND
}

Corresponding author: Ronak Raheja, drronakraheja@gmail.com

\begin{abstract}
Statins are the primary class of medication used to lower serum cholesterol concentration for both primary and secondary prevention of cardiovascular disease. Muscle pain is a frequent adverse effect of statins. Severe myonecrosis leading to clinical rhabdomyolysis is rare.
\end{abstract}

We encountered a 63-year-old male with a medical history of hypertension, type 2 diabetes mellitus, and coronary artery disease with angioplasty in 2008 and 2020. He was started on rosuvastatin $40 \mathrm{mg}(0-0-1)$ along with dual anti-platelets post angioplasty and was discharged home. He traveled back to his hometown and noticed progressive symmetric muscle weakness with decreased urine output. After visiting another hospital he presented to us with severe proximal muscle weakness and acute renal failure. Laboratory investigations were initiated which demonstrated clinically significant derangement in serum creatinine phosphokinase, serum creatinine, urine myoglobin along with deranged liver enzymes. He was subjected to nerve conduction studies for his muscle weakness which was normal and electromyography showed abnormal spontaneous muscle activity in all examined muscles (fibrillations, positive sharp waves, and pseudomyotonic discharges) suggestive of an irritable myopathy. The medication was stopped and he was treated with eight cycles of hemodialysis until his muscle weakness and laboratory parameters improved. He was then discharged with some improvement in muscle weakness. On two week follow-up, the patient showed partial improvement after discontinuation of all lipid-lowering medication.

Received 08/27/2020 Review began 09/11/2020 Review ended 10/09/2020 Published 10/13/2020

๑) Copyright 2020 Chitralli et al. This is an open access article distributed under the terms of the Creative Commons Attribution License CC-BY 4.0., which permits unrestricted use, distribution, and reproduction in any medium, provided the original author and source are credited.
Categories: Cardiology, Internal Medicine, Nephrology

Keywords: statin-induced necrotizing autoimmune myopathy, myopathy, proximal myopathy, myoglobin, intensity of statin dosing

\section{Introduction}

Statins are the primary class of medication used to lower serum cholesterol concentration for both primary and secondary prevention of cardiovascular disease. Muscle pain is a frequent adverse effect of statins with an incidence of about $15 \%$ of users taking the medication [1]. It is important for treating physicians to classify candidates for high-intensity statin therapy versus low-intensity statin therapy before initiating treatment. Analyses conducted by the United States Food and Drug Administration have reported the rate of fatal rhabdomyolysis as 0.15 per 1 million statin prescriptions dispensed [1]. Although muscle toxicity remains a concern, severe myonecrosis leading to clinical rhabdomyolysis is rare, affecting perhaps $0.1 \%$ of patients [2].

We use this paper to briefly review and differentiate between the possible spectrum of muscle pathologies ranging from myalgia, myopathy, myositis, myonecrosis, and clinical rhabdomyolysis in accordance with the 2014 National Lipid Association definitions. Our goal is to briefly recap the Indications for statin use as per the American Heart Association /American College of Cardiology guidelines and remind treating physicians about considering the intensity of statin therapy that patients are on. We briefly present a case of rosuvastatin-induced myopathy.

\section{Case Presentation}

We encountered the case of a 63-year-old male with a past medical history of type 2 diabetes mellitus for 20 years, hypertension for 10 years, and coronary artery disease with percutaneous transluminal coronary angioplasty in 2008. He presented in January 2020 to a nearby hospital with complaints of chest pain where he was evaluated and on angiography was found to have triple vessel disease and appropriate stents were placed on February 5, 2020. He was then discharged home with changed medication. He was started on rosuvastatin $40 \mathrm{mg}$ in place of his $20 \mathrm{mg}$ atorvastatin and other medication changes as shown in Table 1. 


\section{Cureus}

\section{Old medication (from 2008 to 2020)}

[Atorvastatin $20 \mathrm{mg}+$ aspirin $75 \mathrm{mg}$ combination pill] $(0-1-0)$

[Cilnidipine $10 \mathrm{mg}+$ telmisartan $40 \mathrm{mg}$ combination pill] (1-0-0)

[Metoprolol succinate $50 \mathrm{mg}$ ] (0-0-1)

Glyceryl trinitrate $2.5 \mathrm{mg}$ as needed for chest pain

Titrated insulin and metformin variably
New medication (after procedure 2020)

Aspirin $75 \mathrm{mg}(0-1-0)$, ticagrelor $90 \mathrm{mg}(1-0-1)$, rosuvastatin $40 \mathrm{mg}(0-0-1)$

[Telmisartan $40 \mathrm{mg}+$ metoprolol 50 combination pill] (1-0-0)

Cilnidipine $10 \mathrm{mg}$ twice daily (1-0-1)

Stopped

Tablet gliclazide $5 \mathrm{mg}$ (1-0-1), tablet vildagliptin $50 \mathrm{mg}$ 1-0-1 mixture Insulin (30/70) 16-0-16 units

\section{TABLE 1: Comparison of new medication post-procedure versus old medication}

Post-procedure after a few medication changes, he traveled back to his hometown and first noticed progressive symmetric muscle weakness. At first, he was not able to walk or rise from his bed. He did not report any sensory loss or difficulty swallowing. He reported worsening fatigue, weakness, nausea, and decreasing urine output. He presented to his primary hospital where he was found to have acute kidney injury with a serum creatinine of 6.4 with hyperkalemia.

He then presented to our hospital where physical examination showed preserved higher mental functions, intact cranial nerves with visual defects, and normal sensory findings with reduced proximal muscle strength symmetrically in both upper and lower limbs (2/5) without any weakness of distal muscles in both upper and lower limbs strength (5/5). There were no fasciculations, swelling of the affected muscles, or skin rash. Muscle bulk was unaffected (4/5). Reflexes were universally weak. Other systems were within normal limits.

The course of progression of muscle weakness in relation to his serum creatinine phosphokinase levels and serum creatinine levels has been tabulated in Table 2 . In view of severe renal failure and oliguria, he was initiated on hemodialysis through a temporary hemodialysis catheter and he was dialyzed on a schedule as shown in Table 1. Even after stopping rosuvastatin, he continued to be dialysis dependant for the next two weeks. His creatine phosphokinase levels steadily came down and his urine output gradually started improving after two weeks. His myopathy also improved significantly and he was discharged. On follow-up, his creatinine levels came to $3.8 \mathrm{mg} / \mathrm{dl}$ (Figure 1) and he was weaned of hemodialysis. He was also advised not to take statins and discuss with his cardiologist for shifting him to an alternative lipid-lowering medication in the future if the need should arise.

\begin{tabular}{|c|c|c|c|c|}
\hline Date & Event & $\begin{array}{l}\text { Creatinine }(\mathrm{mg} / \mathrm{dl}) \\
\text { reference }(0.5-1.2 \\
\mathrm{mg} / \mathrm{dL})\end{array}$ & $\begin{array}{l}\text { CPK (IU) } \\
\text { reference (40- } \\
400)\end{array}$ & Power (out of 5) \\
\hline 04/Feb/2020 & $\begin{array}{l}\text { One day before the procedure (the last } \\
\text { dose of atorvastatin } 20 \mathrm{mg} \text { was given) }\end{array}$ & 1.5 & & Power \\
\hline 05/Feb/2020 & Day of the procedure & 1.5 & & Power 5/5 \\
\hline $06 / \mathrm{Feb} / 2020$ & $\begin{array}{l}\text { One day after the procedure (rosuvastatin } \\
40 \mathrm{mg} \text { was initiated) }\end{array}$ & 1.4 & & Normal power $\mathrm{b} / \mathrm{s}$ \\
\hline 14/Feb/2020 & Une-week post-procedure & 2.2 & & $\begin{array}{l}\text { Proximal muscle weakness } \\
\text { first experienced power } 4 / 5\end{array}$ \\
\hline $22 / \mathrm{Feb} / 2020$ & I wo weeks post-procedure & 4.00 & & $\begin{array}{l}\text { Weakness progressing power } \\
3 / 5\end{array}$ \\
\hline 29/Feb/2020 & Three weeks post-procedure & 3.98 & & $\begin{array}{l}\text { Persistent weakness power } \\
2 / 5\end{array}$ \\
\hline 05/Mar/2020 & Presented to our hospital & 6.46 & & $\begin{array}{l}\text { Persistent weakness power } \\
2 / 5\end{array}$ \\
\hline 06/Mar/2020 & $\begin{array}{l}\text { Day } 1 \text { at our center rosuvastatin } 40 \mathrm{mg} \\
\text { was discontinued }\end{array}$ & 3.71 & $1,30,36$ & $\begin{array}{l}\text { Persistent weakness power } \\
2 / 5\end{array}$ \\
\hline
\end{tabular}




\section{Cureus}

07/Mar/2020 Day 2/cycle 1 of hemodialysis

08/Mar/2020 Day 3/cycle 2 of hemodialysis

09/Mar/2020 Day 4

10/Mar/2020 Day 5 cycle 3 of hemodialysis

11/

Day 6

12/Mar/2020 Day 7/cycle 4 of hemodialysis

13/Mar/2020 Day 8 at our hospital

14/Mar/2020 Day 9/cycle 5 of hemodialysis

15/Mar/2020 Day 10/cycle 6 of hemodialysis

16/Mar/2020 Day 11 at our hospital

17/Mar/2020 Day 12/cycle 7 of hemodialysis

18/Mar/2020 Day 13/cycle 8 of hemodialysis

Day 14/discharged home with advice to

19/Mar/2020

follow-up regular hemodialysis

21/Apr/2020

Lab test near home after intermittent hemodialysis

4.00

27/Apr/2020 Phone follow-up
Persistent weakness power 2/5

Persistent weakness power $2 / 5$

Persistent weakness power 2/5

Persistent weakness power 2/5

Persistent weakness power 2/5

Persistent weakness power 2/5

Persistent weakness power 2/5

Gradual improvement power 3/5

Gradual improvement power 3/5

Gradual improvement power

Gradual improvement power 3/5

Gradual improvement power $3 / 5$

Gradual improvement power $3 / 5$

Weakness improved significantly $(4 / 5)$

Weakness Improved significantly $(4 / 5)$

Weakness improved to $(5 / / 5)$

\section{TABLE 2: Progression in regard to creatinine $(\mathrm{mg} / \mathrm{dl})$ and CPK levels}

CPK: creatinine phosphokinase levels.

Muscle strength was graded in accordance with the medical research council (MRC grading) as following: 1 - slight flicker movements scene in the muscle group; 2 - muscle contraction present but with gravity eliminated; 3 - muscle contraction present and contracts against gravity; 4 - muscle contraction present against some resistance; 5 - normal and strong muscle contraction. 


\title{
Cureus
}

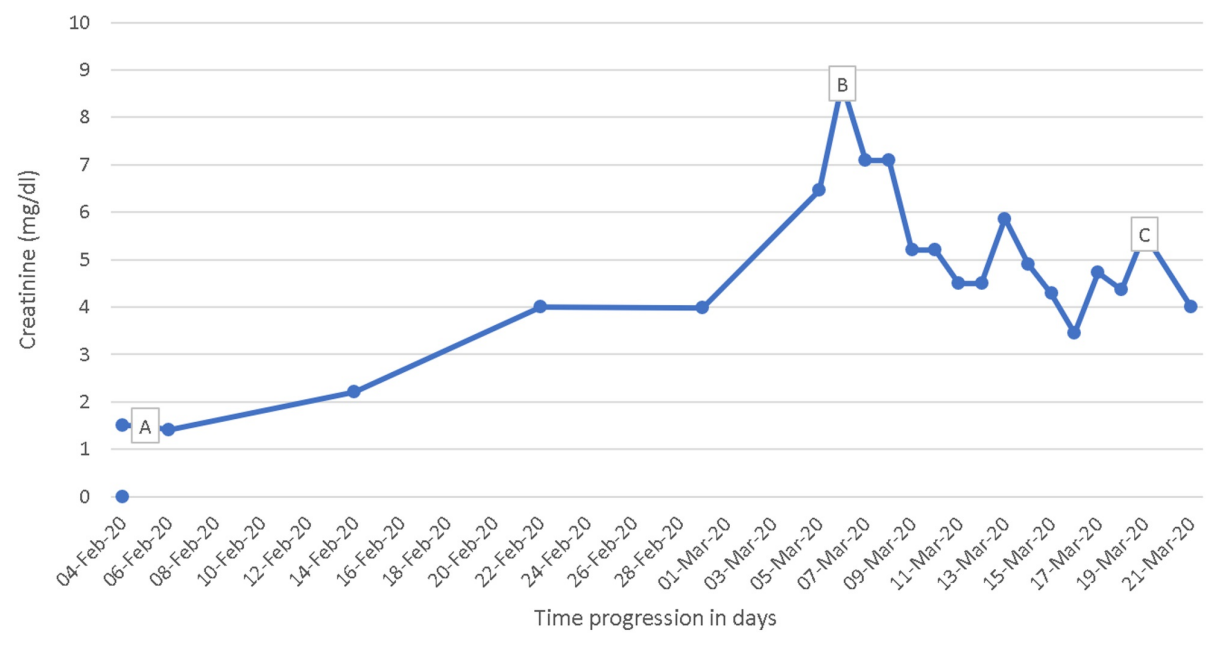

FIGURE 1: Creatinine level variation (mg/dl)

(A) The date of coronary stent placement: 06/Feb/2020 (creatinine: 1.50); (B) the date he presented to our hospital: 07/Mar/2020 (creatinine: 8.71); (C) the date he was discharged home: 21/Mar/2020 (creatinine: 5.54).

\section{Discussion}

Muscle syndromes associated with statins vary from myalgias, myopathy, myositis, and muscle injury. Druginduced myopathy is among the most common causes of muscle disease. It ranges from mild myalgias with or without weakness to chronic myopathy with severe weakness and can also cause massive rhabdomyolysis with acute renal failure. Below we have compiled a table (Table 3) to help review muscle pathologies as defined by the 2014 National Lipid Association Statin Muscle Safety Task Force.

\section{Muscle pathologies overview}

\begin{abstract}
Normal CK level. Myalgia symptoms can be described as similar to what would be experienced with a viral syndrome such as influenza.
\end{abstract}

Myopathy Muscle weakness (not due to pain), with or without an elevation in CK level.

Myositis Muscle inflammation.

Myonecrosis

Elevation in muscle enzymes compared with either baseline CK levels or the upper limit of normal that has been adjusted for age, race, and sex.

\section{Mild}

myonecrosis

3- to 10-fold elevation in CK.

Moderate

myonecrosis

10- to 50 -fold elevation in CK.

\section{Severe}

myonecrosis

50-fold or greater elevation in CK.

Clinical Myonecrosis + myoglobinuria or myonecrosis + acute renal failure (an increase in serum creatinine of at least 0.5 rhabdomyolysis $\mathrm{mg} / \mathrm{dL}$ ).

\section{TABLE 3: Muscle pathologies overview}

CK: creatine kinase.

Overall, the Statin Safety Expert Panel reaffirms the general safety of statin therapy. It is the belief of the Panel members that in most patients requiring statin therapy that the potential benefits of statin therapy outweigh the potential risks [3]. 


\section{Cureus}

\section{Mechanism of statin-induced myopathy}

Statin-associated myopathy demonstrates that a single agent may cause myopathy by more than one mechanism: (i) autoimmune mechanisms; (ii) direct myotoxicity - on histopathological examination vacuolated muscle fibers may occur with the use of statins; (iii) genetic factors - a trial of statins found an association between a specific solute carrier organic anion transporter 1B1 (SLCO1B1) variant (SLCO1B1*5) and an increased risk of mild adverse events [4].

In a study among 2,52,460 patients treated with lipid-lowering agents, 24 cases of hospitalized rhabdomyolysis occurred during treatment [5]. The American Heart Association /American College of Cardiology 2013 makes a person eligible for statin therapy by recommending it for those as listed in Table 4 [6-8].

Indications for statin use

ASCVD

LDL C > $190 \mathrm{mg} / \mathrm{dL}$

Primary prevention in type 2 diabetics (age between 40 and 75 years) with LDL C 70 to $189 \mathrm{mg} / \mathrm{dL}$

Primary prevention of estimated 10-year risk of ASCVD $>7.5 \%$ and age 40 to 75 years

\section{TABLE 4: Indications for lipid-lowering medication as per AHA}

AHA: Ameican heart association, ASCVD: atherosclerotic cardiovascular disease, LDL C: low-density lipoprotein C.

Very elderly people pose a troubling dilemma for the cardiovascular community, guideline writers, and clinical practitioners. Although they are at high risk of a cardiovascular event by virtue of their age alone, evidence of statin use is very limited in this age group [9]. The statin-associated muscle symptoms scoring system clinical index (SAMS-CI), was proposed by the expert task force for evaluating statinassociated symptoms [9]. We used the SAMS-CI which demonstrated a high probability for statin-induced muscle symptoms.

Although there are many guidelines for the management of statin therapy, the concept of the maximum tolerated statin therapy is of extreme importance and has been added to the American College of Cardiology 2018 guidelines. We recommend treating physicians consider the intensity of dosing statin medication carefully. We have summarized the aspects of dosing statin medication in Table 5. It is also noteworthy to discuss that the concept of treating to target low-density lipoprotein levels (LDL) has been removed by the task force. 


\section{Cureus}

\begin{tabular}{|c|c|c|c|}
\hline Dosing type & High intensity & Moderate intensity & Low intensity \\
\hline Aim & $\begin{array}{l}\text { On average lowers } \\
\text { LDL } C \text { by more than } \\
50 \%\end{array}$ & $\begin{array}{l}\text { On average lowers LDL } C \text { between } \\
30 \% \text { and } 50 \%\end{array}$ & On average lowers LDL C less than $30 \%$ \\
\hline Choice of drugs & $\begin{array}{l}\text { Include atorvastatin } \\
(40-80 \mathrm{mg}) \\
\text { rosuvastatin (20-40 } \\
\mathrm{mg})\end{array}$ & $\begin{array}{l}\text { Include atorvastatin (10-20mg) } \\
\text { rosuvastatin (5-10 mg) }\end{array}$ & -- \\
\hline Choice of drugs & -- & $\begin{array}{l}\text { Simvastatin }(20-40), \text { pravastatin }(40- \\
80) \text {, lovastatin }(40 \mathrm{mg}) \text {, fluvastatin }(80 \\
\mathrm{mg}) \text {, pitavastatin }(2-4 \mathrm{mg})\end{array}$ & $\begin{array}{l}\text { Simvastatin (up to } 10 \mathrm{mg} \text { ), pravastatin (up to } 20 \\
\mathrm{mg} \text { ), lovastatin (up to } 20 \mathrm{mg} \text { ), fluvastatin (up to } \\
40 \mathrm{mg} \text { ), pitavastatin (up to } 1 \mathrm{mg} \text { ) }\end{array}$ \\
\hline \multicolumn{4}{|l|}{ Indications } \\
\hline If LDL C > 190 & $\begin{array}{l}\text { First choice if age } \\
\text { below } 75 \text { years }\end{array}$ & $\begin{array}{l}\text { If unable to tolerate high dose or age } \\
>75 \text { years }\end{array}$ & If unable to tolerate a moderate dose \\
\hline $\begin{array}{l}\text { If atherosclerosis } \\
\text { ACS/stroke/vascular } \\
\text { procedures }\end{array}$ & $\begin{array}{l}\text { First choice if age } \\
\text { below } 75 \text { years }\end{array}$ & $\begin{array}{l}\text { If older than } / 5 \text { years or unable to } \\
\text { tolerate a high dose }\end{array}$ & Only if unable to tolerate a moderate dose \\
\hline Diabetics & $\begin{array}{l}\text { diabetics with } \\
\text { ASCVD risk }>7.5 \%\end{array}$ & $\begin{array}{l}\text { First choice in diabetics with ASCVD } \\
\text { risk less than } 7.5 \%\end{array}$ & If unable to tolerate the moderate dose \\
\hline Nondiabetics & $\begin{array}{l}\text { First choice if } \\
\text { ASCVD risk }>7.5 \%\end{array}$ & $\begin{array}{l}\text { Optional consider if ASCVD risk } \\
<7.5 \%\end{array}$ & If unable to tolerate \\
\hline
\end{tabular}

\section{TABLE 5: Dosing of statin summary}

AHA: Ameican Heart Association, ASCVD: atherosclerotic cardiovascular disease, LDL C: low-density lipoprotein C.

It is important to rule out the obvious causes of rhabdomyolysis such as trauma, hyperthermia, severe metabolic derangements, high-dose steroid use, and congenital myopathies including mitochondrial diseases. Glucocorticoid-induced myopathy is usually painless. Most other myopathies have some element of pain and tenderness involved. In polymyalgia rheumatica, the erythrocyte sedimentation rate is increased but creatinine kinase levels are usually not significantly elevated. In inflammatory myopathies, there will be elevation in both erythrocyte sedimentation rate and creatinine phosphokinase levels. The mechanism of statin-induced rhabdomyolysis has been schematically illustrated in Figure 2. 


\section{Cureus}

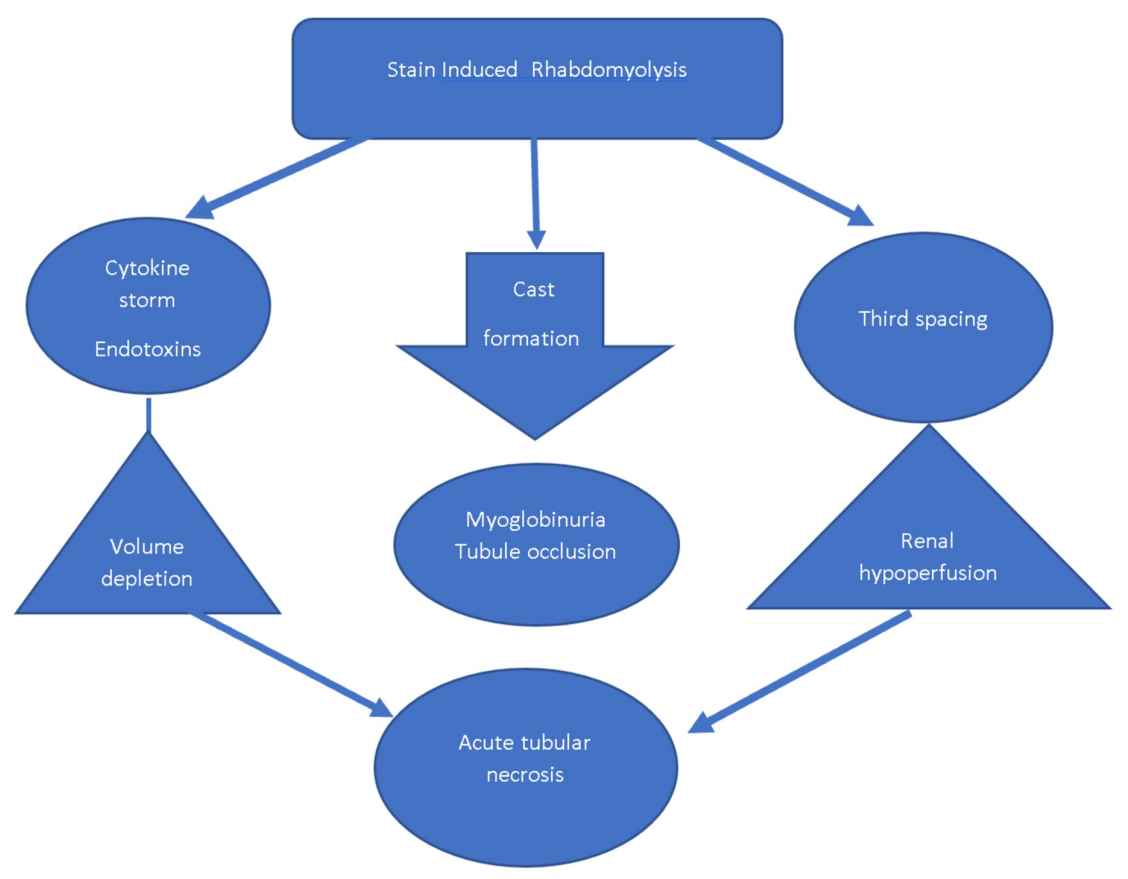

FIGURE 2: Mechanism of statin-induced acute kidney injury

In statin-induced myopathy usually, the erythrocyte sedimentation rate will be normal, but creatinine phosphokinase will be elevated. In the approach to weakness, we should use a systematic flow to identify the site of lesion as either upper motor neuron, lower mortar neuron, nerve end terminals, neuromuscular junction, or the muscle itself. Then, we should consider electrolyte imbalances or poisons.

Management of statin-induced muscle pathology should be guided by the extent of creatinine phosphokinase elevation. If creatinine phosphokinase is elevated to more than 10 times, then the upper normal limit indicates stopping the medication, stabilizing the patient even to the extent of hemodialysis to manage acute kidney injury. After discontinuation of statin therapy, we recommend repeating the lipid profile on a later date and switching to a low-dose alternative lipid-lowering therapy regimen.

\section{Conclusions}

It is important to identify statin-induced myonecrosis. It is also important for the general physician to consider dosing statin carefully. It may be advisable to educate patients on statin-induced side effects when using a high dose. We attempted to review the spectrum of myopathies and indications for statin use. Stains may rarely show clinical rhabdomyolysis and it should always be considered as a differential diagnosis in patients presenting with weakness and renal failure following a cardiac intervention. Careful analysis of drug history will help in early diagnosis and prompt treatment of statin-induced myopathy. Stain-induced myopathy usually indicates stopping the medication and possibly switching to an alternative medication or regimen. It should take approximately four months for rosuvastatin-induced rhabdomyolysis to improve if appropriate interventions are taken.

\section{Additional Information}

\section{Disclosures}

Human subjects: Consent was obtained by all participants in this study. Conflicts of interest: In compliance with the ICMJE uniform disclosure form, all authors declare the following: Payment/services info: All authors have declared that no financial support was received from any organization for the submitted work. Financial relationships: All authors have declared that they have no financial relationships at present or within the previous three years with any organizations that might have an interest in the submitted work. Other relationships: All authors have declared that there are no other relationships or activities that could appear to have influenced the submitted work.

\section{References}

1. Kashani A, Phillips CO, Foody JM, Wang Y, Mangalmurti S, Ko DT, Krumholz HM: Risks associated with statin therapy: a systematic overview of randomized clinical trials. Circulation. 2006, 114:2788-2797. 


\section{Cureus}

10.1161/CIRCULATIONAHA.106.624890

2. Grundy SM: Can statins cause chronic low-grade myopathy?. Ann Intern Med. 2002, 137:617-618.

10.7326/0003-4819-137-7-200210010-00015

3. Jacobson TA: NLA task force on statin safety - 2014 update . J Clin Lipidol. 2014, 8:S1-S4.

10.1016/j.jacl.2014.03.003

4. SEARCH Collaborative Group, Link E, Parish S, et al.: SLCO1B1 variants and statin-induced myopathy - a genomewide study. N Engl J Med. 2008, 21:789-799. 10.1056/NEJMoa0801936

5. Graham DJ, Staffa JA, Shatin D, et al.: Incidence of hospitalized rhabdomyolysis in patients treated with lipid-lowering drugs. JAMA. 2004, 292:2585-2590. 10.1001/jama.292.21.2585

6. Goff DC Jr, Lloyd-Jones DM, Bennett G, et al.: 2013 ACC/AHA guideline on the assessment of cardiovascular risk: a report of the American College of Cardiology/American Heart Association Task Force on Practice Guidelines. J Am Coll Cardiol. 2014, 63:2935-2959. 10.1016/j.jacc.2013.11.005

7. Stone NJ, Robinson JG, Lichtenstein AH, et al.: Treatment of blood cholesterol to reduce atherosclerotic cardiovascular disease risk in adults: synopsis of the 2013 American College of Cardiology/American Heart Association cholesterol guideline. Ann Intern Med. 2014, 4:339-343. 10.7326/M14-0126

8. Lambert M: ACC/AHA release updated guideline on the treatment of blood cholesterol to reduce ASCVD risk. Am Fam Physician. 2014, 15:260-264.

9. Mortensen MB, Falk E: Primary prevention with statins in the elderly . J Am Coll Cardiol. 2018, 71:85-94. 10.1016/j.jacc.2017.10.080 